\title{
Health claims according to Article 13 of the EC Regulation: suggested priorities with reference to the Swedish Code on health claims and emphasis on relevance
}

\author{
Susanne Bryngelsson and Nils-Georg Asp
}

SNF Swedish Nutrition Foundation, Lund, Sweden

\begin{abstract}
Based on principles specified in the Swedish Code on health claims and experiences from handling of claims within the Code, priorities that may be useful when establishing a positive list of generic health claims and for responsible use of claims are suggested. One key factor highlighted is that claims should be relevant and meaningful for the consumer. To be useful in choosing a healthy diet, claims should primarily aim to stimulate an intake in agreement with official nutrition recommendations. Claims may thus be considered as relevant primarily for nutrients of which a considerable part of the population has an intake deviating from the recommendations. For vitamins and minerals, commonly involved in many functions in the body, it would be useful to prioritize claims referring to effects considered more important than others. Functions true for all essential nutrients, and/or affected by a large number of dietary factors, would be less relevant to claim for single vitamins and minerals. The relative importance of a specific vitamin or mineral, in relation to other nutrients potentially exerting similar effects, should also be considered. Based on these priorities, and on claims permitted or suggested as examples in the Code, a list of generic claims on vitamins, minerals, fatty acids, carbohydrates, dietary fibre, energy and wholegrain is suggested. Additional issues considered within the Code are also discussed.
\end{abstract}

Keywords: generic; glycaemic index; meaningful; relevant

\section{Introduction}

$\mathrm{H}$ ealth claims on foods have recently been regulated in the European Union (EU), by "Regulation (EC) no 1924/2006 of the European Parliament and of the Council of 20 December 2006 on nutrition and health claims made on foods" (hereafter referred to as the Regulation) $(1,2)$. According to Article 13.3 of the Regulation, the European Commission (COM) will establish a positive list of claims other than those referring to the reduction of disease or to children's development and health, i.e. Article 13 claims (hereafter referred to as the Article 13.1 list). The Article 13.1 list will be established by 31 January 2010 after consulting the European Food Safety Authority (EFSA). All claims in the Article 13.1 list may be used without any further application or notification procedure, provided that the claim and product comply with the Regulation and any conditions of use specified for the claim in question, including the nutrient profiles to be established. The competent authorities (CA) in all Member States, in Sweden the National Food Administration (NFA), can submit suggestions to the COM by 19 January 2008 (1; Article 13.2). In addition to the positive list of authorized claims that will be included in the Community Register a list of rejected claims will be established.

The exact procedure for how the CAs will act to collect national suggestions for Article 13.1 claims is not specified by the Regulation. Some Member States, e.g. Finland (3) and the UK (4), have collected claims used on the market or made open calls for suggestions. Extensive lists of claims have also been compiled by various organizations. For example, the Confederation of the Food and Drink Industries in the EU (CIAA) (5) recently published a list of 759 claims, including claims for nutrients, 
other substances (e.g. probiotic strains), foods, diets and botanicals (e.g. herbs and spices, and parts of or extracts from such foods).

In Sweden the NFA has invited two organizations for co-ordinating the proposal from the food industry on health claims according to Article 13.1. As the co-ordinating body within the Swedish Food Sector's Code of Practice on health claims (see below), SNF Swedish Nutrition Foundation (6) will suggest claims applicable to regular foods, while the Swedish food supplement producer's association (Svensk Egenvård) (7) will co-ordinate health claims related to food supplements. NFA will also accept proposals for health claims submitted by other food business operators, but recommends that other operators first consult these two organizations, e.g. regarding the level of scientific evidence that can be assumed to be required.

In Sweden claims will be submitted to NFA by 30 September 2007. Before a national list is submitted to the COM, NFA will, among other things, consult the Medicinal Products Agency regarding claims on the borderline between health claims and medicinal claims. The final list will be established by COM, after a scientific evaluation made by EFSA $(1,2)$.

The Swedish Code in relation to the Regulation The Swedish Code "Health Claims in the Labelling and Marketing of Food Products. The Food Sector's Code of Practice" (hereafter referred to as the Code) was introduced in 1990 (8). SNF Swedish Nutrition Foundation has been the co-ordinating body within the Code since its introduction. Principals of the Code are the Swedish Food Federation and the Swedish Food Retailers Federation.

The Code is applicable to regular foods, but explicitly not to supplements and other foods appearing as medicinal products, e.g. in the form of capsules and pills. The Regulation, in contrast, is applicable also to food supplements. Furthermore, claims according to the Code are limited to foods contributing to a nutritionally balanced diet, and nutritional profiles are defined in the 2004 version $(8,9)$, with a general reference to the NFA's regulation on the use of a particular symbol, i.e. the keyhole symbol (10). Within the Regulation, nutritional profiles will be established by the COM by 19 January 2009 (1, Article 4).

Three categories of health claims are defined by the Code: generic nutrient function claims, generic reduction of disease risk claims (nine allowed connections) and product-specific physiological claims (abbreviated to PFP in Swedish) (8). The Regulation does not explicitly classify health claims into generic and product-specific claims, but Article 13 claims based on "generally accepted scientific evidence" (Article 13.1 claims) could be assumed to be primarily generic, while the use of those based on "newly developed scientific evidence", i.e. innovative claims (Article 13.5) may be limited to certain food products or food categories. However, the exact delimitation between Articles 13.1 and 13.5 is not yet clear. Therefore, in addition to the generic claims in the SNF list in focus here (Table 1), product-specific claims evaluated and approved within the Code will be proposed by SNF for the Article 13.1 list.

\section{The SNF list of generic claims}

Based on approved claims, examples of claims and principles specified in the Code, a list of generic Article 13.1 claims has been compiled (hereafter referred to as the SNF list) (Table 1). Since the Code allows generic claims for nutrients, energy and wholegrain only, the SNF list primarily includes such claims. Generic claims for other substances than nutrients, e.g. lycopene, and botanicals are not included, since no such health claims have been evaluated within the Code.

\section{Reworded reduction of disease risk claims}

Reduction of disease risk claims, approved within the Code, would by definition fall under Article 14, for which a specific application and full evaluation is required (11). However, similarly to nutrient function claims, these claims are based on generally accepted knowledge, in fact the same body of scientific evidence that is behind the general nutrition recommendations nationally and internationally. Since listing of such claims is not an option at present, another possibility suggested by SNF would be to reword these claims in terms of maintenance and promotion of health rather than reduction of disease risk. For example, "reduction of risk of osteoporosis" in relation to the calcium content of foods, would correspond to "maintenance/promotion of healthy/strong bones". Within the UK Joint Health Claims Initiative (JHCI), wording in terms of "healthy heart" and "helps maintain heart health" has been used to avoid direct reference to disease (12). 
Table I. Generic health claims suggested by the Swedish Code/SNF for the positive list of Article I3.I claims ${ }^{\mathrm{a}}$

\begin{tabular}{|c|c|c|c|c|}
\hline No. & $\begin{array}{l}\text { Suggested } \\
\text { classification }^{\mathrm{b}}\end{array}$ & Food/food component & Health relationship & Example of wording ${ }^{c}$ \\
\hline \multicolumn{5}{|c|}{ Vitamins } \\
\hline 1 & $13.1 \mathrm{a}$ & Thiamin & Nerve function & Thiamin is necessary for normal function of the nerve system \\
\hline 2 & $13.1 \mathrm{a}$ & Folate/folic acid & $\begin{array}{l}\text { Foetal development/ } \\
\text { pregnancy outcome }\end{array}$ & $\begin{array}{l}\text { Folate/folic acid is necessary for normal growth of the foetus/unborn } \\
\text { baby/Folate/folic acid is necessary for normal pregnancy outcome }\end{array}$ \\
\hline 3 & $13.1 \mathrm{a}$ & Folate/folic acid & Blood formation & Folate/folic acid is necessary for normal formation of red blood cells \\
\hline 4 & $13.1 \mathrm{a}$ & Vitamin $B_{12}$ & Blood formation & $\begin{array}{l}\text { Vitamin } B_{12} \text { is necessary for normal formation of red blood cells. People } \\
\text { eating only plant foods may have a low intake of vitamin } B_{12}\end{array}$ \\
\hline 5 & $13.1 \mathrm{a}$ & Vitamin $\mathrm{B}_{12}$ & Nerve function & $\begin{array}{l}\text { Vitamin } B_{12} \text { is necessary for normal function of the nerve system. People } \\
\text { eating only plant foods may have a low intake of vitamin } B_{12}\end{array}$ \\
\hline 6 & I3.1a & Vitamin C & $\begin{array}{l}\text { Iron absorption/blood } \\
\text { formation }\end{array}$ & $\begin{array}{l}\text { Vitamin } C \text { in a meal helps iron uptake, and thereby contributes red blood } \\
\text { cell formation }\end{array}$ \\
\hline 7 & 13.1a & Vitamin D & $\begin{array}{l}\text { Calcium absorption/bone } \\
\text { health }\end{array}$ & $\begin{array}{l}\text { Vitamin } D \text { is necessary for calcium uptake, and is thereby important for the } \\
\text { normal structure of bone }\end{array}$ \\
\hline \multicolumn{5}{|c|}{ Minerals } \\
\hline 8 & 13.1a & Calcium & Bone health & Calcium is necessary for the normal structure of bone \\
\hline 9 & $13.1 \mathrm{a}$ & lodine & Thyroid function & $\begin{array}{l}\text { lodine is necessary for normal thyroid function/normal production of } \\
\text { thyroid hormones, and thereby contributes to normal metabolism }\end{array}$ \\
\hline 10 & $13.1 \mathrm{a}$ & Iron & Blood formation & Iron is necessary for the formation of red blood cells \\
\hline 11 & $13.1 \mathrm{a}$ & Potassium $^{d}$ & Blood pressure & Potassium may help to maintain a healthy low blood pressure \\
\hline 12 & $13.1 \mathrm{a}$ & Selenium & Antioxidant function & Selenium is necessary for antioxidative functions in the cell \\
\hline 13 & 13.1a & Sodium/salt & Blood pressure & A diet low in salt may help to maintain a healthy low blood pressure \\
\hline \multicolumn{5}{|c|}{ Macronutrients } \\
\hline 14 & I3.1a & Fatty acids: hard/saturated & Cholesterol levels & $\begin{array}{l}\text { A diet low in hard fat/saturated fatty acids may help to maintain healthy } \\
\text { cholesterol levels in the blood }\end{array}$ \\
\hline 15 & $13.1 \mathrm{a}$ & Fatty acids: hard/saturated & Heart health & $\begin{array}{l}\text { A diet low in hard fat/saturated fatty acids may help to maintain a healthy } \\
\text { heart }\end{array}$ \\
\hline 16 & $13.1 \mathrm{a}$ & $\begin{array}{l}\text { Fatty acids: long-chain omega-3 from } \\
\text { fish }\end{array}$ & Heart health & $\begin{array}{l}\text { A diet high in omega- } 3 \text { fatty acids from fish may help to maintain a healthy } \\
\text { heart }\end{array}$ \\
\hline 17 & $13.1 \mathrm{a}$ & Dietary fibre & Bowel regularity & Dietary fibre helps to maintain bowel regularity \\
\hline 18 & $13.1 \mathrm{a}$ & $\begin{array}{l}\text { Soluble dietary fibre (beta-glucan) } \\
\text { from oats and barley }\end{array}$ & Cholesterol levels & $\begin{array}{l}\text { A diet high in soluble fibre (beta-glucan) from oats/barley may help to } \\
\text { maintain healthy cholesterol levels in the blood }\end{array}$ \\
\hline 19 & 13.1a & $\begin{array}{l}\text { Soluble dietary fibre (beta-glucan) } \\
\text { from oats and barley }\end{array}$ & Heart health & $\begin{array}{l}\text { A diet high in soluble fibre (beta-glucan) from oat/barley may help to } \\
\text { maintain a healthy heart }\end{array}$ \\
\hline 20 & $13.1 \mathrm{a}$ & Carbohydrates in pasta products ${ }^{\mathrm{e}}$ & Blood glucose response & $\begin{array}{l}\text { Carbohydrates in pasta products provide a low and slow blood sugar } \\
\text { response/have a low glycaemic index (Gl) }\end{array}$ \\
\hline 21 & $13.1 \mathrm{a}$ & $\begin{array}{l}\text { Carbohydrates in products other } \\
\text { than pasta }{ }^{f}\end{array}$ & Blood glucose response & $\begin{array}{l}\text { Foods with a low glycaemic index }(\mathrm{Gl}) \text { give a low and slow blood glucose } \\
\text { response }\end{array}$ \\
\hline \multicolumn{5}{|c|}{ Others } \\
\hline 22 & I3.Ic & Energy & Body weight & $\begin{array}{l}\text { Foods with a reduced energy content may help to maintain a healthy body } \\
\text { weight/A diet with reduced energy content may contribute to a lower } \\
\text { body weight }\end{array}$ \\
\hline 23 & $13.1 \mathrm{a}$ & $\begin{array}{l}\text { Products free from carbohydrates } \\
\text { fermentable by caries bacteria }\end{array}$ & Dental health & $\begin{array}{l}\text { Foods free from sugar(s) and other carbohydrates broken down by } \\
\text { bacteria in the mouth may help to maintain healthy teeth }\end{array}$ \\
\hline 24 & $13.1 \mathrm{a}$ & Wholegrain & Heart health & $\begin{array}{l}\text { A healthy lifestyle and a well-balanced diet high in wholegrain may } \\
\text { contribute to maintaining a healthy heart }\end{array}$ \\
\hline
\end{tabular}

${ }^{a}$ Conditions of use as specified by the Code. See (8) Appendix I (claims no I-II and 20) and Appendix 2 (claims no I3-19 and 22-24). For claim no. 2I, see ref. (8), Box I.

bI3.Ia and 13.Ic as defined by Article 13.I of the Regulation (I). Claim nos 6-8, 10 and 12 are given as examples in the Code; see ref. (8), Appendix I.

'The examples aim to illustrate how claims might be worded. Type of wording allowed will be decided within the Regulation.

${ }^{d}$ An upper level for the content of sodium is expected to be included in the nutrient profiles, to be established $(I$, Article 4$)$.

eNot applicable to autoclaved pasta products.

${ }^{f}$ Conditions of use as specified by the Code; see ref. (8), Box I. 


\section{Focusing on relevance}

Important delimitations for the SNF list are given by two basic principles of the Code, namely that allowed health claims shall (i) be consistent with official Swedish Nutrition Recommendations and (ii) refer to functions relevant for Swedish consumers.

In the Regulation the matter of relevance is not explicitly highlighted, and it is therefore not known to what extent this factor will be considered when EFSA evaluates the health claims. However, it is stated that wording and presentation of health claims should be taken into account in the opinion of the EFSA and in subsequent procedures, to ensure that the claims are "truthful, clear, reliable and useful for the consumer in choosing a healthy diet" (1; clause 29). Possibly, "useful" may be interpreted as "meaningful" as indicated in the Swedish translation of the Regulation. In the EFSA guidance for the application for authorization of a health claim it is stressed that the evidence used to support a claim should demonstrate the extent to which the claimed effect of the food/constituent is relevant for human health (11, p. 5).

Although there are worldwide guidelines on nutrition and health claims (13), there are no official agreements, nationally or internationally, as to how to define a relevant and meaningful claim. According to the Regulation, health claims must be scientifically substantiated and understandable by the average consumer. To be useful in choosing a healthy diet, it is suggested that claims should also aim to stimulate an intake of nutrients/other substances/foodslfood components in agreement with official nutrition recommendations. For generic health claims it is desirable that they contribute to a healthy diet on a population level. Claims referring to improved performance (physical and mental) and well-being may also be considered as relevant and meaningful.

\section{Selection of vitamins and minerals}

With this background, health claims for vitamins and minerals may be considered as relevant and meaningful primarily for those of which a considerable part of the population has an intake lower than recommended. For the SNF list, 25\% was regarded as a suitable limit to define "a considerable part of the population". Accordingly, vitamins and minerals primarily selected were those of which $25 \%$ or more of the population is estimated to have a lower intake (14) than recommended in the Nordic Nutrition Recommendations (NNR) (15). By this procedure, vitamins $\mathrm{A}, \mathrm{B}_{1}$ (thiamin), $\mathrm{B}_{2}$ (riboflavin), $\mathrm{C}, \mathrm{D}, \mathrm{E}$ and folate, calcium, potassium, iron, magnesium, selenium and zinc (men) were included, while niacin, phosphorus, and vitamins $\mathrm{B}_{6}$ and $\mathrm{B}_{12}$ were excluded. A more liberal limit, corresponding to $5 \%$ of the population having an intake below the recommended intake would add also those four, whereas setting the limit to $50 \%$ would exclude also thiamin and magnesium.

Less than $25 \%$ of the population has a lower intake of vitamin $B_{12}$ than recommended. However, claims regarding the connection between this vitamin and "blood formation" and "normal nerve function" were considered as relevant for vegans, i.e. for people excluding all animal products from their diet. Vitamin $B_{12}$ was therefore added to the list, with a remark that the wording of a $\mathrm{B}_{12}$ claim should reflect that vegans are the main target group.

For vitamin A, the claim "Vitamin $\mathrm{A}$ is found in visual pigments and is important for night vision. Product X contains vitamin A" was listed in the Swedish Code as an example of a scientifically true claim that is irrelevant for Swedish conditions (8; Appendix 1). Furthermore, the span within which the intake is considered safe is smaller for vitamin A than for other vitamins (15). Therefore, health claims for foods high in vitamin A may lead to overconsumption, especially if combined with supplements. Vitamin A was therefore excluded.

Not all vitamins and minerals are included in the dietary survey used as reference (14), e.g. iodine, copper, biotin and pantothenic acid, and for these a comparison of estimated and recommended intake cannot therefore be made. Of these, only iodine is included in the SNF list, since the intake of this mineral relies on certain foods, particularly fortified salt (15). In contrast, copper, biotin and pantothenic acid are widely distributed in foods and deficiency of these nutrients is generally not known to occur.

\section{Considerations for selected vitamins and minerals}

In addition to the scientific basis, an important consideration is what kind of claims regarding the relevant nutrients can be regarded as meaningful to and understandable by the average consumer. For example, general claims for vitamins and minerals, e.g. "needed for normal growth, normal reproduction, etc.", are by definition true for all essential 
nutrients. To claim such effects for single vitamins or minerals is therefore less relevant, and may be misleading. Vitamins and minerals are commonly involved in many different functions in the body, and for one single substance many claims may therefore be scientifically true. However, one or a few effects, considered as more important than the others, can preferably be selected. Similarly, it would be useful to consider the relative importance of a specific vitamin or mineral for a certain effect, in relation to other nutrients. Furthermore, for functions affected by a large number of dietary factors claims referring to one single nutrient may be misleading. For example, unspecific claims related to the immune system are therefore in general questionable.

With this background, the following specific considerations were made for the selection of claims regarding vitamins and minerals for the SNF list.

Vitamin $B_{2}$. Although claims such as "Riboflavin contributes to the normal release of energy from foods" and "Vitamin $\mathrm{B}_{2}$ contributes to the normal transport and metabolism of iron in the body" are scientifically true (16), they are hardly understandable by the consumer, and may even be misleading. A claim related to healthy skin and mucous membranes can also be regarded as having questionable consumer relevance. Therefore, no claim was included in the SNF list regarding vitamin $B_{2}$.

Vitamin D. The requirement for vitamin $\mathrm{D}\left(\mathrm{D}_{3}\right)$ can be completely satisfied by solar exposure of the skin. However, at the latitude of the Nordic countries vitamin $\mathrm{D}$ deficiency may occur if the diet is devoid of this vitamin (15). Vitamin D contributes to calcium absorption from the intestine, and is essential for the mineralization of the skeleton. There are also indications that vitamin D plays other roles, e.g. related to cancer, autoimmune disease, infections and muscle strength, but such effects cannot yet be regarded as well established. Therefore, the connection between vitamin D and bone health is prioritized for the Article 13.1 list.

Zinc. The claim "Zinc is needed for many of the body's enzyme systems" has, since the revision in 2004, been included in the Code as an example of relevant nutrient function claims. However, as discussed above it was considered questionable to include such general claims for individual minerals.
Other scientifically true claims for zinc may refer to effects on immune system, cell division and healthy skin (16). However, all of these are very general and therefore questionable, as discussed above. Claims regarding the connection between zinc and normal growth would refer to the development of children, and relate to Article 14. No claim on zinc was therefore included in the SNF list.

Iron and iodine. Claims such as "Iron/iodine is necessary for normal neurological development of embryos/foetus" may be scientifically true (16). However, since this is not the main health issue related to these minerals such claims were not included in the SNF list.

Magnesium. Of the many functions of magnesium in the body, one identified as important was a possible beneficial effect on blood pressure. However, even though there is some epidemiological support for a relation between low intake of magnesium and hypertension it has not yet been conclusively established that too low a dietary intake of magnesium is any primary causative factor for this outcome (15). The relative importance of magnesium for effects on blood pressure is therefore so far considered questionable, especially in relation to other dietary factors (e.g. sodium) affecting blood pressure.

\section{Wording}

A number of factors must be considered for appropriate wording of health claims. The Regulation highly stresses that health claims should be understandable by the average consumer, but they should also reflect the scientific basis and act as an effective marketing tool. In addition, borderline issues (e.g. Article 13 versus Article 14 claims and health claims versus medicinal claims) must be considered (see below), as well as the overall impression in combination with other information provided, on the packaging or elsewhere.

Wordings suggested in the SNF list aim to illustrate what claims on the selected health relationships may look like. However, the wordings have not been fully evaluated, and the suggested claims should so far be considered as preliminary and regarded as "type of claim", rather than suggestions on the final and/or only wording allowed. At this point there are still some question marks relating to what wording will be considered appropriate to 
comply with the Regulation. For example, it is not yet known whether there will be any distinction among "necessary for", "helps to", "needed to" and "contributes to".

\section{The two-step principle}

The Swedish Code stresses that wordings of generic claims should ensure that they are not perceived as product specific, i.e. they must not indicate that the particular product in question has a certain effect on disease risk reduction. It would be especially important to put such claims in the context of a balanced diet. For this purpose, the two-step principle was introduced in the Code, and required for disease risk reduction claims (8). The two-step principle means that (i) the connection between diet and a physiological function/reduced risk of disease and (ii) the product's composition are given separately, but in connection to each other. Although also suggested for nutrient function claims in the Code, this principle has not been applied in the SNF list, but it should be noted that all examples in the Codex Guidelines are worded according to the twostep principle (13).

\section{Conditions of use}

The Code pinpoints that the amount of the food product normally consumed must be such that it has appreciable significance for a balanced diet, and that the product's composition must be such that it is relevant to the claim. However, similarly to the wording of claims, setting appropriate conditions is a challenge. On the one hand, required levels of the active substance should be high enough to guarantee that the food product bearing the claim will actually contribute to the effect claimed. If not, the consumer may be misled. On the other hand, claims may stimulate consumption of a range of fortified products with risk of overconsumption, especially in combination with food supplements.

In the Code, conditions of use were specified by the last revision, in 2004 (8; Appendices 1 and 2). For nutrient function claims for vitamins and minerals, the general criterion is that the food product shall be a "source of" the substance in question, i.e. the food shall contain at least $15 \%$ of the recommended daily intake (RDI) per $100 \mathrm{~g}$, as specified by the Council Directive on nutrition labelling for foodstuffs (17). Furthermore, normal daily intake of the product shall provide at least $15 \%$ of RDI of the actual vitamin or mineral.
Whenever possible, the conditions of use to be suggested in the SNF list will be similar to, or based on the criteria specified within the Code. However, for some claims the conditions in the SNF list have to be slightly modified to comply with the conditions for nutrition claims as specified in the Annex of the Regulation (1).

\section{References}

For generic claims, the scientific body of evidence should be the same as for official nutrition recommendations, i.e. surveys such as the WHO TRS 916 report (18), the NNR (15), reports from the US Institute of Medicine, Food and Nutrition Board (19), and the forthcoming European Population Reference Intakes (PRI). Such references are therefore primarily used for the SNF list, together with selected reports published by JHCI and the US Food and Drug Administration (FDA), e.g. for vitamins and minerals (16), oats $(20,21)$, barley (22) and wholegrain $(23,24)$. For the PFPs evaluated and approved, which will also be suggested by SNF for the national Article 13.1 list, the evaluation reports (25-34) and relevant studies referred therein will be listed as references.

\section{Some borderline issues}

It is not yet known whether claims referring to cholesterol level, blood pressure and a healthy heart (e.g. "maintain a healthy level of/lowers cholesterol", "maintain a healthy blood pressure/lowers blood pressure" and "maintain a healthy heart") will be accepted as Article 13 claims. There is a possibility that such claims will be regarded as implied reduction of disease risk claims and thereby fall under Article 14. Claims related to "healthy heart", or the like, may be considered too vague, and therefore be acceptable only in combination with a more specific claim, e.g. "helps to maintain a healthy cholesterol level" (1; Article 10.3). In view of these ongoing discussions, claims regarding both cholesterol levels/blood pressure and heart health are included in the SNF list.

Claims referring to the normal development of embryos (e.g. for folate) may also be expressed as normal pregnancy outcome, and regarded as claims targeted at fertile women (primarily those planning pregnancy) and thereby eligible for the Article 13.1 list, as suggested here. However, if considered as a health claim referring to children's growth and development this claim would fall under Article 14. 


\section{Issues considered within the Code}

Some issues related to the Article 13.1 list, considered within the Code, are commented on below.

\section{Glycaemic index claims}

The concept of glycaemic index (GI) is a welldefined way of ranking foods high in carbohydrates owing to their effect on the blood glucose response. Thus, "low GI" would be well defined once an upper value for what is considered as "low" is set. Within the Code this upper limit was set to 55, using glucose as a reference $(\mathrm{GI}=100)(8$; Box 1$)$. In the Regulation, GI claims might be considered as Article 13.1a claims, i.e. claims referring to the role of a nutrient (carbohydrates) in the functions of the body (blood glucose response). However, since many factors, including food matrix and food processing, influence the GI value of a food, determinations in humans are required on each product. Experiences from handling GI claims within the Code strongly stress the importance of consulting expertise for a standardized evaluation of GI determinations. A premarketing evaluation would be useful to avoid misleading GI claims, at least until the methodology for GI determinations has been further developed and harmonized.

Since specific health outcomes of a low GI food or diet, e.g. reduced risk of a disease or beneficial effects on a risk factor for disease, satiety or body weight, have not been considered as well established (35), no such claims are included in the SNF list.

\section{Probiotic and prebiotic claims}

The effects of probiotic bacteria vary among strains, and even among species. There is, so far, no scientific agreement on criteria for claims on effects of probiotic bacteria in general (e.g. "Probiotic bacteria stimulate a healthy flora of bacteria in the intestine", "... promotes the balance of the intestinal flora" or "... helps the body to protect itself"), although such general claims for probiotics are frequently used on the market. Furthermore, the effects of a specific strain/species may vary depending on, for example, the food matrix. Within the Code, probiotic claims have therefore been considered as PFP, requiring scientific documentation on the final product. Those evaluated and approved within the Code will be suggested by SNF for the national Article 13 list.

The Code includes a generic nutrient function claim for dietary fibre referring to "bowel regularity". More specific claims on prebiotic effects, e.g. "stimulates bifidobacteria" or "increases calcium absorption" have not been scientifically evaluated within the Code, and are therefore not included in the SNF list.

\section{Fruit and vegetables}

Epidemiological studies suggest a connection between intake of fruit and vegetables and a reduced risk of cardiovascular disease and certain types of cancer (15), and there is a consensus that most European consumers should increase their intake of fruit and vegetables. According to WHO TRS 916, the evidence for beneficial effects of increased intake of fruit and vegetables (including berries) on reduced risk of cardiovascular disease and obesity is "convincing" (18). Within the Code a general reference to the official recommendations from the NFA of a daily intake of at least $1 / 2 \mathrm{~kg}$ fruit and vegetables is suggested as useful in marketing and labelling (8; Appendix 1). The possibility of making more specific health claims for fruit and vegetables, e.g. in relation to heart health, has been discussed, but so far the scientific data have not been considered conclusive enough for any decision.

\section{Antioxidants}

It is commonly suggested that the beneficial health effect of fruit and vegetables can be explained, at least partly, by their content of antioxidants. There is also increasing interest in claiming that food products are "high in antioxidants", based, for example, on the relative total antioxidant capacity of the product in question, compared with other foods and measured by in vitro methods. Furthermore, in the final version of the Code claims on the connection between certain vitamins, i.e. vitamin $\mathrm{C}$, vitamin $\mathrm{E}$ and beta-carotene (provitamin $\mathrm{A}$ ), and cell protection owing to antioxidant actions were listed as examples of nutrient function claims (8). However, in the light of the inconclusive results from available intervention studies with specific antioxidants, health claims for antioxidants may be questionable for the time being. Furthermore, there are no official nutritional recommendations for dietary antioxidants (15). There are also insufficient data relating the in vitro determination of, for example, total antioxidant capacity to health outcomes. There are therefore several reasons to question whether antioxidant claims are suitable for the Article 13.1 list. An exception would be for 
selenium, which is necessary for proper functions of certain endogenous enzymes exerting antioxidant activity in cells (15).

\section{Unsaturated fatty acids}

It is well established that saturated fatty acids affect levels of blood cholesterol negatively. Therefore, the intake of these should be limited and for most people reduced (15). A reduced intake of saturated fatty acids may be achieved either by a decreased total fat intake, or by exchanging saturated fatty acids for unsaturated fatty acids. However, there is less evidence that an increased intake of unsaturated fatty acids per se would contribute substantially to a beneficial effect on blood cholesterol. For most consumers there are also good reasons not to increase total fat intake, which may be a practical consequence of promoting a higher proportion of unsaturated fatty acids in the diet. Therefore, claims on connections between fat quality and effects on cholesterol levels should primarily focus on saturated fatty acids.

\section{Fish and omega-3 fatty acids}

Available evidence strongly suggests that eating fish is related to a reduced risk of fatal coronary heart disease, and that this effect, at least partly, is mediated by the long-chain omega- 3 fatty acids in fish (15). A main hypothesis today is that the beneficial effect of long-chain omega-3 fatty acids is mainly due to their antiarrhythmic effects, but they may also contribute by positive effects on triglycerides and blood pressure. It is also possible that other constituents of fish, e.g. proteins, contribute to a beneficial health effect. According to the Code a generic claim on the connection between long-chain omega-3 fatty acids from fish and heart health has been allowed since 1997 (8). However, more specific claims on long-chain omega-3 fatty acids or claims for fish in general have not been evaluated within the Code, and are therefore not included in the SNF list.

\section{Beans, lentils and legumes - low GI}

Similarly to the case for pasta products, GI tables indicate that beans, lentils and legumes in general are low GI foods $(36,37)$, and there is a common idea that those foods always give a low and slow blood sugar response after a meal. However, it is not yet well known how commercial food processing commonly applied to these foods (e.g. autoclaving) affects their GI. Therefore, it is considered premature to list a generic GI claim for these foods.

\section{Carbohydrates - physical performance}

Dietary carbohydrates are essential for the reconstitution of the body's glycogen reserves after physical activity, for example, and extremely low intake of carbohydrates will impair physical performance (15). However, carbohydrates are present in most foods consumed in a common diet, and it may therefore be considered as a less relevant claim. Claims referring to improved physical performance, owing to improved carbohydrate composition or other characteristics, would seem relevant primarily for specific foods developed for and targeted at athletes.

\section{Dietary fibre - satiety and body weight}

Several physiological effects of foods high in dietary fibre, e.g. low energy density, may contribute to body-weight management, and the evidence that dietary fibre may protect against weight gain and obesity has been graded as "convincing" (18). However, the scientific support for a generic health claim on the connection between dietary fibre and satiety/body weight may be premature and has so far not been evaluated within the Code. Therefore, such claims are not included in the SNF list.

\section{Concluding remarks}

The Regulation highly stresses that health claims shall be understandable by the average consumer, but it is less clear to what extent consumer relevance will be considered as an important factor when the COM establishes a Community Register of approved claims. However, according to EFSA, the evidence supporting health claims should demonstrate the extent to which the claimed effect of the food/food constituent is relevant for human health (11). Such considerations would be in line with the basic principles applied within the Code, and would be helpful for the consumer. Selecting relevant and meaningful claims is a delicate and challenging task on a national level, and even more so on a European level. A procedure for the selection of vitamins and minerals to be prioritized to be on the Community list, from a Swedish perspective, is suggested. This procedure, and other standpoints taken here, are based on the principles of the Swedish Code and the practical experiences from handling health claims 
within the Code since 1990. Arguments that only scientific evidence should be considered when approving claims for the Article 13.1 list, or other arguments for selection than those suggested here, could be raised. However, even if not applied on a regulatory basis, priorities as suggested here may also be applied voluntarily by food business operators, with the aim of using health claims in a responsible and sustainable manner. If a large number of less relevant health claims were going to be used in the labelling and marketing of food products in the future, there would be a risk that these would cover the more important claims, and confuse the consumer. Such a situation would not facilitate consumers' trust in health claims, which appears to be a prerequisite for the successful achievement of the goals of the Regulation, and for health claims to constitute useful marketing tools in the long run.

\section{References}

All internet references were accessed on 15 August 2007.

1. Corrigendum to Regulation (EC) No. 1924/2006 of the European Parliament and of the Council of 20 December 2006 on nutrition and health claims made on foods. Official Journal of the European Union 2007;50. eur-lex.europa.eu/LexUriServ/site/en/oj/2007/1_012/ 1_01220070118en00030018.pdf

2. Laser-Reuterswärd A. The new EC regulation on nutrition and health claims foods. Scand J Food Nutr 2007; 51: 100-6.

3. Vaiha K, Sarlio-Lähteenkorva S. Report on health claims used in marketing of foodstuffs in Finland. Helsinki: Finnish Food Safety Authority Evira; 2007. www.evira.fi/portal/en/food/current_issues/?a = ViewMes sage $\&$ id $=421$

4. Food Standards Agency. London, UK. www.foodstan dards.gov.uk

5. Confederation of the Food and Drink Industries in the EU. Brussels, Belgium. www.ciaa.be

6. SNF Swedish Nutrition Foundation. Lund, Sweden. www.snf.ideon.se

7. Svensk Egenvård [Swedish Selfcare]. Stockholm, Sweden. www.svenskegenvard.se

8. Asp N-G, Bryngelsson S. Health claims in the labelling and marketing of food products: the Swedish Code of Practice in a European perspective. Scand J Food Nutr 2007; 51: 107-26.

9. Health Claims in the Labelling and Marketing of Food Products. The Food Sector's Code of Practice. Revised version September 2004. www.hp-info.nu/SweCode_ 2004_1.pdf
10. National Food Administration's regulations on the use of a particular symbol. LIVSFS 2005:9. Uppsala: National Food Administration. www.slv.se/upload/nfa/ documents/food_regulations/Keyhole_2005_9.pdf

11. Scientific and technical guidance for the preparation and presentation of the application for authorization of a health claim. Opinion of the Scientific Panel on Dietetic Products, Nutrition and Allergies. EFSA J 2007; 530: 1-44. www.efsa.europa.eu/en/science/nda/nda_opinions/ claims/ej530_guidance_health_claims.html

12. Joint Health Claims Initiative. Leatherhead, UK. www.jhci.org.uk

13. Guidelines for use of nutrition and health claims. Rome: Codex Alimentarius; 2004. www.codexalimentarius.net/ download/standards/351/CXG_023e.pdf

14. Becker W, Pearson M. Riksmaten 1997-1998. Dietary habits and nutrient intake in Sweden 1997-98. 2002. National Food Administration. Uppsala, Sweden.

15. Nutrition Recommendations 2004. 4th edn. Integrating nutrition and physical activity. Nord 2004:3. Copenhagen: Nordic Council of Ministers; 2004. http://www. norden.org/pub/sk/showpub.asp?pubnr $=2004: 013$

16. Final Technical Report (JHCI/76/3), Joint Health Claims Initiative, UK (Code of Practice). http:// www.food.gov.uk/multimedia/pdfs/jhci_healthreport.pdf

17. Council Directive 90/496/EEC of 24 September 1990 on nutrition labelling for foodstuffs. Official Journal of the European Union 1990;L276:40-4. eur-lex.europa.eu/ LexUriServ/LexUriServ.do?uri = CELEX:31990L0496: EN:HTML

18. Diet, Nutrition and the Prevention of Diseases. Report of a joint FAO/WHO expert consultation. WHO Technical Report Series 916. Geneva: World Health Organization; 2003.

19. Dietary Reference Intakes Series. Washington, DC: Institute of Medicine of the National Academies. http://www.iom.edu/CMS/3788/4574/45127.aspx

20. Final report (oats-blood cholesterol). Leatherhead, UK: Joint Health Claims Initiative; 2004. www.jhci.org. uk/approv/oats.htm

21. Final rule. Food labeling: health claims; soluble fiber from whole oats and risk of coronary heart disease. Food and Drug Administration, USA; 1997. www.cfsan.fda.gov/ 1rd/fr970331.html

22. Final rule. Food labeling: health claims; soluble dietary fiber from certain foods and coronary heart disease. Food and Drug Administration, USA; 2006. www.fda. gov/ohrms/dockets/98FR/04p-0512-nfr0001.pdf

23. Final report (wholegrain-heart health). Leatherhead, UK: Joint Health Claims Initiative; 2002. www.jhci.org. uk/approv/wgrainh.htm

24. Health claim notification for whole grain foods. Food and Drug Administration, USA; 1999. www.cfsan.fda. gov/ dms/flgrains.html

25. Almér L-O, Hermansen K, Vessby B. Statement concerning evaluation of the scientific documentation behind a product specific health claim (Primaliv). Lund: SNF Swedish Nutrition Foundation; 2002. www.hp-info.nu/prodsp/Finalreport_Primaliv.pdf 
26. Aro A, Bach Knudsen K-E, Lovegrove J, Wood P. Statement concerning evaluation of the scientific documentation behind a product-specific health claim (Primaliv muesli) SNF Swedish Nutrition Foundation, Lund, Sweden. 2006.

27. Johnson O, Mensink RP, Pedersen JI. Statement concerning evaluation of the scientific documentation behind a product specific health claim (Becel pro.activ spread). Lund: SNF Swedish Nutrition Foundation; 2002. http://www.hp-info.nu/prodsp/Finalreport_Becel. pdf

28. Johnson O, Mensink RP. Statement concerning evaluation of the scientific documentation behind a product specific health claim (Becel pro.activ milk drink). Lund: SNF Swedish Nutrition Foundation; 2004. http:// www.hp-info.nu/prodsp/Finalreport_Becelmilkdrink. pdf

29. Johnson O, Mensink RP. Statement concerning evaluation of the scientific documentation behind a product specific health claim. (Becel pro.activ yoghurt drink, minidrink). Lund: SNF Swedish Nutrition Foundation; 2006. http://www.hp-info.nu/prodsp/Finalreport_ Becelshot.pdf

30. Brummer RJ, Danielsson Å, Lauritsen K. Statement concerning evaluation of the scientific documentation behind a product specific health claim (Proviva fruit drink). Lund: SNF Swedish Nutrition Foundation; 2003. http://www.hp-info.nu/prodsp/finalreport_proviva. pdf

31. Griffin BA, Mutanen M, Pedersen JI. Statement concerning evaluation of the scientific documentation behind a product specific health claim (Julia/Hjärtans Lust). Lund: SNF Swedish Nutrition Foundation; 2004. http://www.hp-info.nu/prodsp/Finalreport_Julia.pdf

32. Johnson O, Mensink RP, Pedersen JI. Statement concerning evaluation of the scientific documentation behind a product specific health claim (Benecol spread). Lund: SNF Swedish Nutrition Foundation; 2006. http:// www.hp-info.nu/prodsp/Benecolspread1.pdf

33. Johnson O, Mensink RP, Pedersen JI. Statement concerning evaluation of the scientific documentation behind a product specific health claim. (Benecol yoghurtdrink). Lund: SNF Swedish Nutrition Foundation; 2006. http://www.hp-info.nu/prodsp/Benecolyoghurt.pdf

34. Brummer RJ, Danielsson Å, Lauritsen K. Statement concerning evaluation of the scientific documentation behind a product specific health claim. (LGG ${ }^{\circledR}$ Plus). Lund: SNF Swedish Nutrition Foundation; 2007. http:// www.hp-info.nu/prodsp/FinalreportLGG. @pdf

35. Arvidsson-Lenner R, Asp N-G, Axelsen M, Bryngelsson S, Haapa E, Järvi A, et al. Glycaemic index. Relevance for health, dietary recommendations and food labelling. Scand J Food Nutr 2004; 48: 84-94.

36. Foster-Powell K, Holt SHA, Brand-Miller JC. International table of glycaemic-index foods. Am J Clin Nutr 2002; 76: 5-56.

37. Henry KCJ, Lightowler HJ, Strik CM, Renton H, Hails S. Glycaemic index and glycaemic load values of commercially available products in the UK. Br J Nutr 2005; 94: 922-30.

\section{Susanne Bryngelsson}

SNF Swedish Nutrition Foundation

Ideon Science Park

SE-223 70 Lund

Sweden

Tel: +46462862284

Fax: + 46462862281

E-mail: susanne.bryngelsson@snf.ideon.se 